\title{
Fifth day fits: a syndrome of neonatal convulsions
}

\author{
D S PRYOR, N DON, AND D C MACOURT \\ St George Hospital, Kogarah, New South Wales, and University of New South Wales, Australia
}

SUMMARY A new syndrome of neonatal convulsions is described. Ninety cases were documented from one maternity hospital between 1973 and 1977. The appearance of this syndrome increased the annual incidence of neonatal convulsions from fewer than 3 to more than 16 per 1000 live births. Fits began on about the fifth day in apparently healthy babies. Investigations and therapeutic trials have not shown the cause. There were no deaths and all babies were discharged from hospital apparently well. The term fifth day fits is suggested with criteria for this diagnosis.

Neonatal fits are often due to asphyxia, birth trauma, hypoglycaemia, or hypocalcaemia, and few lack an apparent cause. The onset of fits is generally within the first 2 days of life but there is a second peak incidence about the sixth day frequently due to hypocalcaemia. Infections and metabolic causes are often responsible for fits starting after the first week of life. ${ }^{1}$

Since June 1973 there has been an increase in the incidence of neonatal convulsions at one maternity hospital in Sydney and a number of apparently normal babies convulse on the fourth or fifth day of life. The reason for these fits is unknown despite careful investigation. The clinical pattern seems distinct from known causes of neonatal fits and the fits are frequently self-limiting with apparently full recovery on discharge from hospital. The problem has been present in several other maternity units in this city and was described in France. ${ }^{2}$

The hospital records for all cases of neonatal convulsions in one hospital during $4 \frac{1}{2}$ years have been examined to try to define the syndrome and find possible causes.

\section{The data}

Hospital records were examined and data were tabulated in relation to any infant in whom fitting was observed between birth and discharge from hospital. The pattern of occurrence of cases by month is shown in Fig. 1. There is no clear seasonal incidence but the annual frequency gradually decreased between 1975 and 1977. The hospital patients consist largely of unselected maternity cases from the surrounding district. There is virtually no domiciliary obstetrics practised. The incidence of fitting per 1000 live births is shown in Table 1. Causes such as trauma or anoxia were obvious in only a few

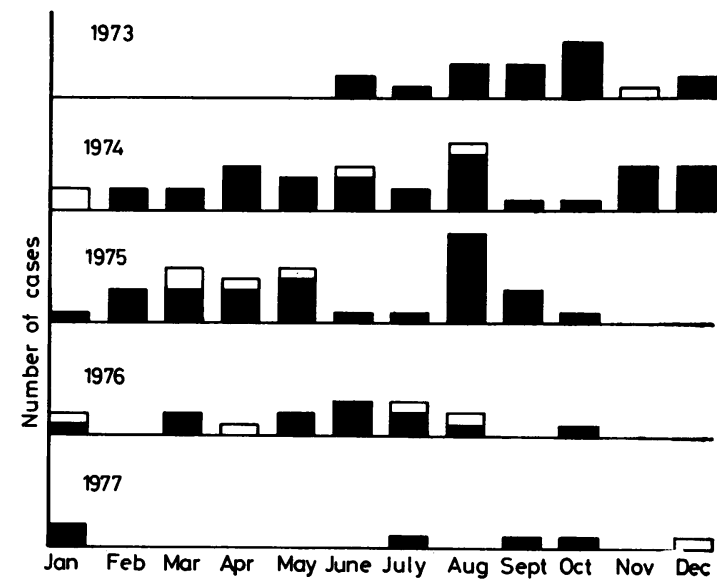

Fig. 1 Month that neonatal convulsions occurred. Black columns denote fifth day fits. Open columns denote other causes of fits.

Table 1 Incidence of infants who had fits

\begin{tabular}{llll}
\hline Year & Live births & Infants with fits & $\begin{array}{l}\text { No of infants who } \\
\text { had fits per 1000 } \\
\text { live births }\end{array}$ \\
\hline 1973 (June to & & & \\
December) & 1011 & 17 & 17 \\
1974 & 2197 & 32 & 15 \\
1975 & 1990 & 32 & 16 \\
1976 & 2324 & 16 & 7 \\
1977 & 2239 & 6 & 3 \\
\hline
\end{tabular}

cases. In most, the clinical pattern was similar, with onset at about the fifth day being the best distinguishing feature (Fig. 2). A number of infants with onset of fits during the first 72 hours of life had an apparent cause of fitting. We have excluded all these early 


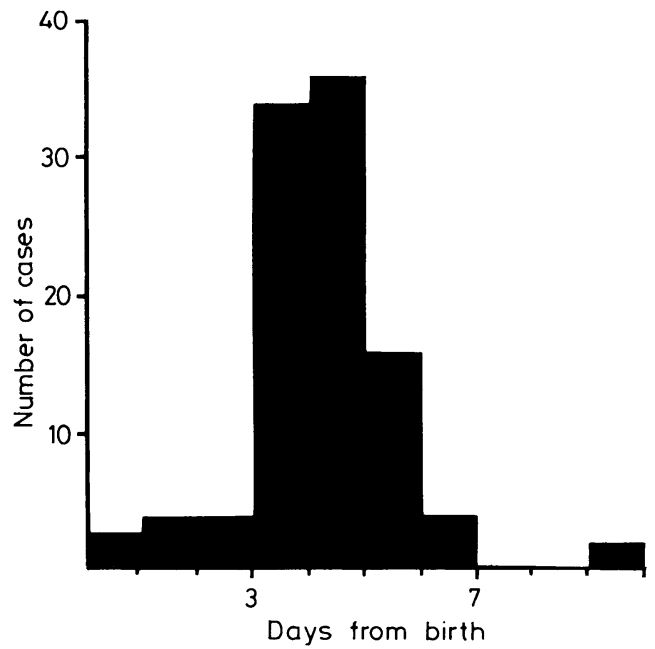

Fig. 2 Time of onset of neonatal convulsions.

onset cases from our analysis. The 2 infants aged 9 days at onset are excluded too.

Of the original 103 cases there remain 90 with onset between 72 hours and 7 days of birth. This was mainly on the fourth or fifth day of life (some 70 cases), with 16 on the sixth day and 4 on the seventh (Fig. 2). These last 4 had onset within the first 9 hours of the seventh day. The apparent sudden peak of cases at 72 hours is confirmed on analysis of the actual hour of onset which was evenly distributed throughout the fourth day.

A control group was created by examining the records of 100 consecutive births starting on 1 July 1974 and 100 consecutive births starting on 1 January 1975. Mean or percentage figures for the control group thus refer to 200 births at the same hospital during the time of the high incidence of fitting and should be representative of the mothers presenting for delivery in this hospital.

\section{The mothers}

The 90 mothers ranged in age from 17 to 39 (mean $26)$ years. The control group mean age was 26 years. Thirty-one $(34 \%)$ were primiparous compared with $42 \%$ of the control group. Eighty-five $(94 \%)$ were married (control 97\%), 4 were single (control $1 \%$ ), and marital status was not recorded in 1 (control $1 \%)$. Seventy-four $(82 \%)$ were classified as private or intermediate ward patients (control $86 \%$ ); $15(17 \%)$ were public or 'hospital' patients (control $14 \%$ ); in one the classification was not recorded.
The mother's country of birth was given as Australia in $61(68 \%)$ (control $69 \%$ ), Yugoslavia in $7(8 \%)$ (control $7 \%$ ), Italy in $4(4 \%)$ (control $4 \%)$, and as other countries in $16(18 \%)$ (control $18 \%$ ).

Maternal blood group was A (31 cases), B (9 cases), AB (5 cases), O (45 cases); 77 were $\mathrm{Rh}$ positive, $13 \mathrm{Rh}$-negative.

\section{Pregnancy and labour}

No particular illness or drug exposure was recorded during the pregnancy or labour and the clinician responsible for each case made careful retrospective enquiry without any apparently relevant facts emerging. Pethidine, diazepam, or nitrous oxide was used during labour in most of the cases. Syntocin was used for induction of labour in $31(34 \%)$ (control $34 \%$ ), artificial rupture of membranes was performed in $36(40 \%)$ (control $29 \%)$. The total number in which labour was induced was $45(50 \%$ ) (control $35 \%$ ).

Epidural anaesthesia was used in $24(27 \%)$ (control $31 \%$ ).

No relationship to individual obstetricians or members of the nursing staff present at delivery could be recognised. Duration of labour ranged from 50 minutes to 19 hours, mean 5 hours 30 minutes (control 5 hours 28 minutes).

Delivery was normal in $47(52 \%$ ) (control $65 \%$ ) and assisted by forceps in $31(34 \%)$ (control $28 \%$ ). Three were breech deliveries (control $0.5 \%$ ).

Eleven $(12 \%)$ were delivered by caesarean section (control $6 \%$ ) and details of this group (Table 2) show trauma, anoxia, or prematurity to be an unlikely primary cause of fits. Also the onset and duration of fitting were comparable with the remainder of the group.

\section{The babies}

There were 52 boys and 38 girls (control 97 boys: 103 girls). Fetal maturity was more than 36 weeks by dates in all but 4 infants. Two of these 4 infants did appear to be preterm as were 3 other infants in whom birthweight was less than $2500 \mathrm{~g}$ (Table 3). No characteristics of fitting in these cases distinguished them from the remainder.

Mean birthweight for the group was $3182 \mathrm{~g}$ (control 3280). Apgar scores recorded at one minute after delivery averaged $7 \cdot 6$ and at five minutes averaged 9.2. Apgar scores of 5 or less occurred in 7 infants. Again the time of onset and pattern of fitting were no different from the remainder.

The infants all received vitamin $\mathrm{K} 1$ by injection and water orally during the first day of life. At least 
Table 2 Caesarean section

\begin{tabular}{rlll}
\hline Case & Onset of fits & Duration of fits & Comment \\
\hline 8 & 3 days 5 hours & 50 hours & Birthweight 2690 g. Apgar scores 3 and 5 \\
19 & 4 days 6 hours & 23 hours & Elective for cephalopelvic disproportion \\
21 & 3 days 9 hours & 35 hours & Failed induction for toxaemia \\
23 & 5 days 2 hours & 1 minute & Fibroid. Classical section \\
24 & 5 days 6 hours & 3 hours & Elective for maternal oedema \\
29 & 3 days 12 hours & 27 hours & Antepartum haemorrhage. Irritable, lethargic baby, feeding poorly \\
34 & 3 days 19 hours & 12 hours & Android pelvis and breech presentation \\
37 & 5 days 10 hours & 15 minutes & Failed induction, breech presentation \\
75 & 3 days 10 hours & 12 hours & Unstable lie. Fetal distress \\
84 & 3 days & 24 hours & Previous caesarean section \\
85 & 4 days 22 hours & 13 hours & Birthweight 2460 g \\
\hline
\end{tabular}

Table 3 Prematurity

\begin{tabular}{|c|c|c|c|c|c|}
\hline Case & Onset of fits & Duration of fits (hours) & Birthweight $(g)$ & Gestation (weeks) & Comment \\
\hline $\begin{array}{l}17 \\
32 \\
35 \\
47 \\
85\end{array}$ & $\begin{array}{l}4 \text { days } 6 \text { hours } \\
4 \text { days } 8 \text { hours } \\
4 \text { days } 12 \text { hours } \\
3 \text { days } 10 \text { hours } \\
4 \text { days } 22 \text { hours }\end{array}$ & $\begin{array}{l}11 \\
12 \\
10 \\
22 \\
13\end{array}$ & $\begin{array}{l}2400 \\
2490 \\
2480 \\
2670 \\
2460\end{array}$ & $\begin{array}{l}36 \frac{1}{2} \\
34 \frac{1}{2} \\
40 \\
35 \\
38\end{array}$ & $\begin{array}{l}\overline{-} \\
\overline{\text { Induced }} \\
\text { Caesarean section }\end{array}$ \\
\hline
\end{tabular}

63 were breast fed initially. They appeared to progress normally.

\section{The fits}

Fits were most often described as multifocal with jerking of limbs or face, often unilateral, and sometimes with apnoea or cyanosis. Their duration was from several seconds up to 2 or 3 minutes. Different patterns of fitting occurred at different times in the same case. No apparent precipitating factors were found but between fits the babies were sometimes noted to be jittery in response to stimulation. Neither apnoea alone nor a jittery response was regarded as a fit, although in some infants the seizures were heralded by apnoeic or cyanotic episodes. The frequency of fitting varied with some infants having fits every few minutes. One had 48 fits recorded within one day; others had only 1 attack, and one had 2 attacks separated by a 3-day interval.

Fitting lasted less than 24 hours in $55(61 \%)$ cases and ranged from a single brief episode to one infant who had seizures for 15 days. Treatment did not consistently alter this duration of fitting (Table 4). Occasionally the end of fitting seemed to be related to administration of an anticonvulsant but other cases did not respond and some stopped within
24 hours without treatment with anticonvulsants. Thirty-seven were treated with phenobarbitone, 54 with phenytoin, 17 with diazepam by intravenous injection, and 10 with paraldehyde. Intravenous calcium was given in 15 cases and intravenous pyridoxine in 22 with no apparent effect.

Each baby remained in hospital until the fits stopped and he appeared to have recovered. There were no deaths. Treatment with anticonvulsants was continued in most infants after discharge from hospital.

Nearly all neonates remained in hospital for at least 5 days. Only one infant was known to have had his first fit after discharge from hospital (on the fifth day). It is possible that other infants had fits after discharge from hospital, but this is unlikely.

\section{Investigations}

Blood sugar was measured by Dextrostix in each infant and in at least 34 a laboratory blood glucose estimation was normal. Haemoglobin level and total and differential white cell counts were performed in nearly every case and were normal, as were the appearances of blood films. Skull $x$-ray films, serum sodium, potassium, and urea levels were all normal. Serum bilirubin levels were performed regularly if

Table 4 Duration of fits and number of infants given particular treatment

\begin{tabular}{|c|c|c|c|c|c|c|c|}
\hline Duration (hours) & Phenobarbitone & Phenytoin & Calcium & Pyridoxine & Paraldehyde & Diazepam & Total cases \\
\hline $\begin{array}{l}<12 \\
12-24 \\
25-36 \\
>36\end{array}$ & $\begin{array}{l}11 \\
21 \\
11 \\
14\end{array}$ & $\begin{array}{r}15 \\
20 \\
9 \\
10\end{array}$ & $\begin{array}{l}3 \\
7 \\
2 \\
3\end{array}$ & $\begin{array}{l}3 \\
9 \\
5 \\
5\end{array}$ & $\begin{array}{l}0 \\
5 \\
4 \\
1\end{array}$ & $\begin{array}{l}2 \\
6 \\
4 \\
5\end{array}$ & $\begin{array}{l}22 \\
33 \\
17 \\
18\end{array}$ \\
\hline
\end{tabular}


jaundice was noted. Phototherapy was given in 3 infants but none had sufficient hyperbilirubinaemia to necessitate exchange transfusion. Cerebrospinal fluid was examined in each infant. It was sterile on culture and frequently xanthochromic with scant polymorphonuclear or mononuclear leucocytes and, occasionally, a number of red blood cells apparently caused by the collecting needle. Protein and glucose levels were normal. Virus cultures of cerebrospinal fluid were negative in the 17 examined and electron microscopical examination in 2 infants showed no virus particles.

Serum calcium levels were measured in 81 infants and ranged from 6.6 to $11 \cdot 2 \mathrm{mg} / 100 \mathrm{ml}(1 \cdot 7-2 \cdot 8$ $\mathrm{mmol} / \mathrm{l})$ with a mean of $9 \cdot 3 \mathrm{mg} / 100 \mathrm{ml}(2 \cdot 3 \mathrm{mmol} / \mathrm{l})$. Only 2 infants had levels below $7 \cdot 4 \mathrm{mg} / 100 \mathrm{ml}$ $(1.9 \mathrm{mmol} / \mathrm{l})$. They were given intravenous and oral calcium causing increased serum levels but fits continued for 17 and 22 hours. Serum magnesium levels were measured at the same time in 79 infants and were normal with a range of 1.6 to $2.8 \mathrm{mg}$ / $100 \mathrm{ml}(0.66$ to $1.15 \mathrm{mmol} / \mathrm{l})$ and a mean of $2.1 \mathrm{mg} /$ $100 \mathrm{ml}(0 \cdot 86 \mathrm{mmol} / \mathrm{l})$. Serum immunoglobulins were normal with a mean IgM level from 22 infants of $25 \cdot 9 \mathrm{~g} / \mathrm{l}$.

Many other investigations were carried out in some infants without an abnormality being found. These were blood, urine, and throat swab cultures for bacteria; cerebrospinal fluid, throat swab, urine, and faecal cultures for viruses; urinary metabolic screening; chest $x$-ray films, cerebral gamma scans and echoscans; antibody titres to Herpes simplex, cytomegalovirus, toxoplasmosis, rubella, varicella/ zoster, respiratory syncytial virus, and vaccinia virus; serum phosphates, copper, and zinc; liver function tests; total serum proteins and electrophoretic pattern, serum ammonia; blood gas analysis; cerebrospinal fluid protein electrophoresis and red cell glucose-6-phosphate dehydrogenase assay.

The water used in feeding was analysed for copper, zinc, cadmium, manganese, lead, and arsenic and no high levels were found. The infant feeds and lactose powder were also normal on analysis.

Electroencephalograms were performed in 71 infants and paroxysmal high voltage mixed frequency activity or focal sharp waves unilaterally or bilaterally were present in 25 records. Clinical fitting occurred in 2 infants during recording and was accompanied by high voltage sharp and slow wave activity. Electroencephalographic monitoring of intravenous infusion of pyridoxine was undertaken in some cases. There was no clinical or electrical change during infusion.

\section{Discussion}

The sudden onset of fitting in apparently normal neonates is rare and the high incidence described here started suddenly in 1973. It appeared to coincide with the department moving into a new building but at the same time other Sydney obstetric hospitals also experienced a similar excess of idiopathic neonatal fits. It is unlikely that cases had occurred earlier without being noticed. The unit normally experienced a much lower total incidence of neonatal fitting than that described in reports from referral hospitals in Great Britain ${ }^{3-5}$ of 8.6 to 14.0 per 1000 live births or the reported Australian experience of 3.8 per $1000^{6}$ and $2 \cdot 8$ per $1000 .^{7}$ The outbreak described here caused the annual incidence to reach 16 per 1000 live births in this hospital in 1975 (Table 1) falling to $2 \cdot 7$ in 1977.

Clinical and laboratory investigations failed to show any of the usual causes of neonatal convulsions in the majority of our cases. The absence of deaths supports our belief that most of these cases represent a new syndrome or one not previously recognised.

Other studies ${ }^{1}$ have shown two peak periods for onset of neonatal fits. (1) Within the first 48 hours fits result frequently from asphyxia, birth trauma, or hypoglycaemia. There were only 7 infants during the period of study with onset of fits before $\mathbf{4 8}$ hours and they did have evidence of anoxia, trauma, or prematurity. The 4 infants with fits between 48 and 72 hours were excluded from further analysis although it could be argued that they are also examples of the syndrome we describe. (2) The second peak of incidence is from 96 to 192 hours $^{3}$ with most fits starting on the fifth, sixth, or seventh day of life. Hypocalcaemia or hypomagnesaemia is generally responsible at this time. They are multifocal in nature and may be multiple. The response to intravenous calcium is prompt and the long-term prognosis benign.

The syndrome we describe has many similarities to the second group. The onset of fitting tended to be earlier, on the fourth or fifth day of life. The fits were multiple, multifocal, and benign. Trial therapy with intravenous or oral calcium was ineffective (Table 4), including the 2 infants with serum calcium levels lower than $1.9 \mathrm{mmol} / \mathrm{l}$. Serum magnesium was recorded in 79 of the 90 infants and was normal.

Hopkins $^{6}$ found hypocalcaemia or hypomagnesaemia, or both, in 30 of a series of 75 cases of neonatal convulsions from an Australian obstetric hospital. The lack of such cases in our series is remarkable and not readily explicable.

From 7 to 10 days infections and metabolic causes become more likely. Our investigations failed to show such factors. If the clinician had reason to suspect hypoglycaemia or infection, specific therapy was given and had no obvious effect. Similarly 
pyridoxine deficiency was excluded by therapeutic trial of intravenous pyridoxine with electroencephalographic control. Laboratory investigations gave no evidence of virus infection. IgM levels did not suggest prenatal infection.

This outbreak of a fairly high incidence of fitting suggests a toxic or infective element in the population with a striking temporal relationship to the time of birth. Many events are also time related to birth, such as admission to hospital, drug administration, initial feeding, and bathing. No special relationship could be seen for factors such as parity, duration of labour, time of rupture of membranes, or of vaginal examination after rupture of membranes. No particular nursery or staff members appeared to be particularly associated with the incidence. Cases occurred after elective caesarean section where the patient was never in the labour ward. Careful enquiry was made concerning possible toxin or drug exposure during pregnancy. No change in feeding practices or formulae could be recognised and the water and milk formulae and additives used for infant feeding were analysed and found to be normal. There was no suggestion that drugs or drug withdrawal could be related to these seizures.

There was a higher incidence with male babies, multiparous mothers, artificial rupture of the membranes, forceps delivery, breech delivery, and caesarean section. This may imply that some cases of fits owing to trauma or anoxia have been included or that such factors increase the likelihood of this syndrome becoming manifest. As shown in cases after caesarean section (Table 2) analysis of the pattern of onset, duration, and other clinical features in these cases does not indicate any difference from the majority of cases who had seemed entirely normal babies. Thus we suggest that anoxia or trauma may be contributory factors but usually the fitting occurs without preceding abnormality.

This syndrome is apparently similar to the cases described as 'the seizures of the fifth day of life' by Dehan et al. ${ }^{2}$ This accords with our term fifth day fits which should be used for idiopathic convulsions beginning between 3 and 7 days after birth in an apparently normal baby. The diagnosis can only be made in individual cases after the exclusion of known causes of fits. The majority start on the fourth or fifth day and the seizures are multifocal and often of short duration. They often persist for less than 48 hours even without anticonvulsant therapy, and are apparently benign. No deaths have occurred in our experience. Follow-up studies are needed to determine the long-term prognosis.

We present these data as it appears to be an important clinical problem and a definition of the clinical features may contribute to the search for the cause.

We thank Dr J B Campbell for allowing us to report findings in patients under his care.

\section{References}

1 Brown J K. Convulsions in the newborn period. Dev Med Child Neurol 1973; 15: 823-46.

2 Dehan M, Quillerou D, Navelet Y, et al. Les convulsions du cinquieme jour de vie: un nouveau syndrome? Arch Fr Pediatr 1977; 34: 730-42.

3 Keen J H. Significance of hypocalcaemia in neonatal convulsions. Arch Dis Child 1969; 44: 356-61.

4 Keen J H, Lee D. Sequelae of neonatal convulsions. Arch Dis Child 1973; 48: 542-6.

5 Brown J K, Cockburn F, Forfar J O. Clinical and chemical correlates in convulsions of the newborn. Lancet 1972; i: 135-9.

6 Hopkins I J. Seizures in the first week of life. Med J Aust 1972; ii: 647-51.

7 Rossiter E J R, Luckin J, Vile A, Ganly N, Hallowes R, Pearson R D. Convulsions in the first three years of life. Med J Aust 1977; ii: 735-40.

Correspondence to Dr D S Pryor, School of Medicine, St George Hospital, Kogarah, New South Wales 2217, Australia.

Received 19 August 1980

\section{Commentary}

\section{J K BROWN, Royal Hospital for Sick Children, Edinburgh}

The onset of convulsions about the fourth or fifth day, multifocal in nature, and with the EEG criteria certainly suggests a metabolic or an infective cause. The authors have excluded most of the commonly accepted metabolic causes of convulsions and there was no evidence of infection after examination of the cerebrospinal fluid (all infants) or after viral cultures of cerebrospinal fluid (in a reasonable number of them). The fact that the fits occurred after moving to a new building demonstrates how subtle some of the environmental changes both in utero and ex utero can be. Despite exhaustive detective work no cause has been found for these and the authors would be grateful for any suggestions from readers as to further investigations.

The paper stresses how a convulsion in the newborn infant can be caused by many factors other than those related to birth, genetic disease, biochemical disorder, or abnormalities of pregnancy. We have seen how the diet of the mother in regard to the content of vitamin D or her exposure to sunlight 